\title{
Transnational Lifelong Education Course in Robotic Systems
}

\author{
Paulo Leitão ${ }^{1,2}$, Juan Carlos Fraile ${ }^{3}$, Vidal Moreno ${ }^{4}$, Robert Harrison ${ }^{5}$, Halis Altun ${ }^{6}$, Armando W. \\ Colombo $^{7}$, Javier P. Turiel ${ }^{3}$, Belén Curto ${ }^{4}$ \\ ${ }^{1}$ Polytechnic Institute of Bragança, Campus Sta Apolónia, Apartado 1134, 5301-857 Bragança, Portugal, pleitao@ipb.pt \\ ${ }_{2}^{2}$ Artificial Intelligence and Computer Science Laboratory, Rua Campo Alegre 102, 4169-007 Porto, Portugal \\ ${ }^{3}$ Universidad de Valladolid, C/ Paseo del Cauce s/n, 47011, Valladolid, Spain, jcfraile@eii.uva.es; turiel@eis.uva.es \\ ${ }^{4}$ Universidad de Salamanca, Plaza de la Merced, s/n, 37008 Salamanca, Spain, \{vmoreno, bcurto\}@usal.es \\ ${ }^{5}$ University of Warwick, Coventry, CV4 7AL, UK, Robert.Harrison@warwick.ac.uk \\ ${ }^{6}$ Mevlana University, Yeni İstanbul Cad. No:235, 42003 Konya, Turkey, haltun@mevlana.edu.tr \\ ${ }^{7}$ University of Applied Sciences Emden/Leer, Constantiaplatz 4, 26723 Emden, Germany, awcolombo@et-inf.fho-emden.de
}

\begin{abstract}
Robotics constitutes a multidisciplinary area, congregating knowledge from different scientific domains. The learning of robotic systems requires the acquisition of multidisciplinary scientific bases, and high integration and synthesis abilities, which is not an easy task. This paper describes the implementation of a lifelong course that aims to provide a global insight on robotics field, introducing the concepts and technologies for different domain applications, namely industrial robotics, autonomous mobile robotics and robotics applied in medicine. This is accomplished in an international framework where individual knowledge and experiences will be confronted in a multidisciplinary level and intercultural environment.
\end{abstract}

\section{INTRODUCTION}

Robotics is a current pinnacle of technical development being present in several sectors of our lives, from industry (e.g., welding, painting and assembling components in the automotive industry) to services (e.g., making guided visits to museums and disarming mining fields), passing for the surgery and rehabilitation of people [1]. Particularly, robotics plays a crucial role in the improvement of enterprises' competitiveness and the quality of life of people.

The robotics field constitutes a multidisciplinary area, congregating knowledge from different scientific domains, namely mathematics, physics, mechanics, electronics, automation, computing, systematization, control and artificial intelligence. Learning programs in robotics are required to answer to a growing and sustainable field in the European domain, namely the need to have qualified human resources to improve productivity, flexibility and competitiveness of enterprises. The learning of these topics requires the acquisition of sound scientific bases, and high integration and synthesis abilities, which is traditionally not easy. In fact, these topics are usually learned in curricula addressing a specific topic of robotics, and often focusing the basic concepts and missing the practical exercise of integrated systems. Remote and virtual laboratories may also be used at high-level education, providing the learning environment to acquire knowledge by operating remote or virtual experiments (see for example, [23]). In another perspective, several summer schools try to provide advanced knowledge in narrow domains of robotics (see for example the Summer School on Social Human-Robot Interaction [4], Summer School on Robotic Vision [5], Summer School on Surgical Robotics [6], and Summer School on Agricultural Robotics [7]). In these events, the learning model mainly incorporates invited talks and tutorials.

The challenge is to cover this gap by creating innovative learning programs that aggregates complementary and best practices in the different topics of robotic systems in a transnational and inter-cultural perspective, providing a significant hands-on experience. This paper describes the implementation of an intensive learning education course, supported by the EU Lifelong program - ERASMUS Intensive Programme [8], which aims to provide global insight knowledge on robotic systems. Similar experiences are reported in the literature, e.g., the one focusing the mechatronics and robotics topics, and involving the cooperation between education and industry institutions [9].

Particularly, the course introduces the concepts and technologies for different domain applications, namely industrial robotics, autonomous mobile robotics and robotics applied in medicine. Students can hands-on exercise different robotic systems and understand the differences in the control strategies for different applications, e.g., the different interaction levels between the robot and a human. This is accomplished in an international framework where the complementary and multidisciplinary knowledge and expertise from several European High-level Education Institutions are possible. The established consortium comprises 6 partners from 5 European countries: Instituto Politécnico de Bragança (IPB) from Portugal, Universidad de Salamanca (USal) from Spain, Universidad de Valladolid (UVa) from Spain, Loughborough University (Lboro) from United Kingdom, Mevlana University (UMev) from Turkey and University of Applied Sciences Emden/Leer (HSEL) from Germany. These institutions offer academic courses (bachelor, master and doctor degrees) in the area of engineering and computer sciences, and have a significant enrolment in national and transnational programs, namely the participation in the Erasmus program for student 
and teachers mobility. Additionally, IPB and USal had already some previous experiences in the field by implementing a joint short course in mobile and autonomous robotics sponsored by the Fundação Rei Afonso Henriques.

The major innovation of this project is the establishment of a learning course in the area of robotics based on the complementary knowledge of a transnational European consortium. Furthermore, the inter-disciplinary nature of the learning education course leads to an innovative environment that allows the exchange of different expertise and learning practices aligned with the Bologna process. This addresses one of the European priorities on Erasmus Intensive Programmes, set out in the 2010 Call for Proposals, namely the presence of a strong multidisciplinary approach.

Other objectives of this lifelong education course include the exchange of expertise and knowledge, and share of learning practices in the field of robotics, and the creation of bridges for future common projects, e.g., joint and/or double academic degree courses and research projects. Particularly, the knowledge, expertise and pedagogical methodologies gathered and shared among the partnership may be used by each partner to introduce improvements into the current contents of original study programs. Note that in spite of their natural differences, the robotic courses included in the learning studies curricula of the participating institutions present comparable similarities to the objectives of the proposed intensive program on robotic systems. This fact allows the recognition of the studies undertaken in this intensive program in the original study plans and constitutes an opportunity to develop the basis for future collaboration through the elaboration of joint and/or double academic degrees.

The rest of the paper is organized as follows: Section II describes the organization of the learning course and Section III presents the contents of the lecturing modules. Section IV overviews the evaluation methodology and Section $\mathrm{V}$ presents the results of the implementation of the described learning education course in two editions and summarizes the achieved innovation and impact. Finally, Section VI rounds up the paper with the conclusions.

\section{Pedagogical Methodology}

The reformulation of the education system through the Bologna agreement creates the opportunity to tune and exchange the different partners' experiences and use this intensive program to implement new methodological processes based in active learning from the students instead of the traditional knowledge transmission by the teaching staff. By building a trusty and accountable program to be fulfilled by all institutions may create possibilities for joint study programs and course fine tuning within Bologna framework.

The proposed intensive program on robotic systems is mainly addressed for the first (bachelor) and second (master) cycles of engineering students, namely from mechanical, electrical and industrial informatics engineering.

\section{A. Organizational Course Schema}

An important objective in the design of the course structure was to ensure the recognition of the acquired competences along the education course by the attribution of 6 ECTS (European Credit Transfer and Accumulation System) [10], which can be accredited in the original student degree. The attribution of 6 ECTS corresponds to 162 workload hours: 60 contact hours and 102 hours of self-dependent study plus assessment. For this purpose, the work load is distributed by three main blocks over the time, as illustrated in Fig. 1: i) the preparation for the course, ii) the course itself, and iii) the elaboration of the mini-project.

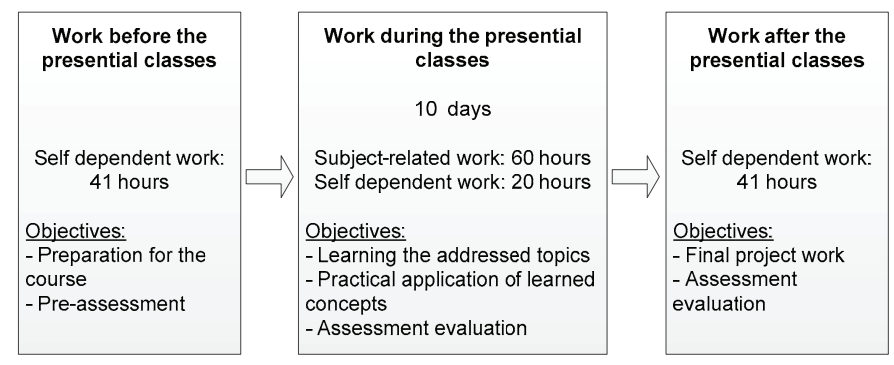

Fig. 1. Schema of the learning education course.

Initially, and aiming to unify the background of the course attendees, some preliminary knowledge is required. For this purpose, the participants are invited to study the pre-requisite topics, e.g., using the bibliography material that is available in the e-learning platform for this period (note that this refers to a platform providing online resources to support a self-learning practice before and during the course, and not directly related to e-learning models, e.g., blending learning practices [11]). This phase is performed in the weeks before the intensive course and takes 41 hours of self-dependent study. At the end, the students are assessed by performing a web test that covers the topics required to enroll the intensive course (also available in the e-learning platform).

The education course takes 10 days of subject-related work, comprising 6 contact hours per day (totalizing 60 contact hours) and 2 hours of self-dependent study per day (totalizing 20 hours). The teaching and learning methodology is based in classroom sessions, where the topics are presented using multimedia facilities, such as power-point slides, videos and demonstrations. Particularly, demonstrations, simulations and videos are used to show, in a realistic way, the topics addressed in the intensive course. The practical and laboratorial works aim to provide hands-on competences and consolidate the acquired learning, being the developed works performed in groups of $2-3$ students. The non-presential component assumes a crucial importance for the success of the learning process (aligned with the Bologna principles), and will be based on the development of laboratorial works and reports about robotics topics.

This course period finishes with a visit to a plant exhibiting robotic systems, which aims to complement the knowledge acquired during the theoretical and practical lectures.

After the 10 days of the intensive course, students have 41 hours of self-dependent study to complete the final miniproject work and to conclude the assessment evaluation. This mini-project work, covering at least one of the topics lectured during the course, is performed individually. 
The lectures, developed didactical material and reports use the English language.

\section{B. ICT and E-learning platform}

An e-learning platform is used to support the pedagogical activities during the course, contributing for a sustainable dissemination and sharing of knowledge about the robotics field. In fact, the e-learning platform will host the learning materials, namely lecture notes, exercises, laboratorial demonstrations, work tests and web quizzes, supporting the realization of the intensive course. These learning contents are uploaded by the responsible of each module, supporting also the early preparation of students for the course.

Additionally, the e-learning platform supports the implementation of new teaching methodologies and practices in the robotics field, by allowing, in a dynamic and fast manner, the cooperative interaction among students and teachers, for exchanging ideas and clarifying doubts. For this purpose, the platform is used as unifying point throughout the intensive course, providing useful functionalities, such as the exchange of e-mails, the participation in forums and the realization of web tests.

\section{COURSE CONTENTS}

The intensive course comprises seven lectures, as illustrated in Fig. 2, comprising theoretical and practical sessions.

\begin{tabular}{|c|c|c|c|c|}
\hline $\begin{array}{l}\text { Module \#1: } \\
\text { Introduction to } \\
\text { robotics } \\
\text { duration: } 3 \text { hours } \\
\text { responsible: IPB }\end{array}$ & \multirow{4}{*}{$\begin{array}{l}\text { Module \#3: } \\
\text { Autonomous } \\
\text { mobile robotics } \\
\text { duration: } 12 \text { hours } \\
\text { responsible: USal }\end{array}$} & \multirow{2}{*}{$\begin{array}{c}\text { Module \#4: } \\
\text { Image processing } \\
\text { and artificial } \\
\text { intelligence in } \\
\text { robotics } \\
\text { duration:6 hours } \\
\text { responsible: UMev } \\
\end{array}$} & \multirow{4}{*}{$\begin{array}{l}\text { Module \#5: } \\
\text { Medical robotics } \\
\text { duration: } 12 \text { hours } \\
\text { responsible: UVa }\end{array}$} & \multirow[t]{2}{*}{$\begin{array}{c}\text { Module \#7: } \\
\text { Entrepreneurship } \\
\text { duration: } 6 \text { hours } \\
\text { responsible: IPB + } \\
\text { HSEL }\end{array}$} \\
\hline \multirow{3}{*}{$\begin{array}{c}\text { Module \#2: } \\
\text { Industrial robotics } \\
\text { duration: } 9 \text { hours } \\
\text { responsible: IPB + } \\
\text { Lboro }\end{array}$} & & & & \\
\hline & & $\begin{array}{c}\text { Module \#6: } \\
\text { Robot as Service } \\
\text { Provider in an } \\
\text { Industrial SoS } \\
\text { Infrastructure }\end{array}$ & & $\begin{array}{l}\text { Evaluation + visit } \\
\text { duration: } 6 \text { hours }\end{array}$ \\
\hline & & $\begin{array}{l}\text { duration: } 6 \text { hours } \\
\text { responsible: HSEL }\end{array}$ & & \\
\hline
\end{tabular}

Fig. 2. Workprogramme for the lectures (presential classes).

The first module, entitled "Introduction to robotics", introduces the robotics field, presenting the contextualization, history, advantages and typical domain applications. It also constitutes the opportunity to present the objective of the intensive course, learning outcomes, pedagogical and evaluation methodologies and calendar of activities.

The second module is dedicated to the thematic of industrial robotics. In detail, this module presents the basic components of a robotic system, classification, sensors and tools, kinematics and dynamics, off-line and on-line programming, operation and security. Some typical industrial applications will take special attention, namely manipulation and welding. The illustration of case studies of applying robotics to real industrial environments is addressed taking the expertise of Lboro. This module comprises a strong practical component related to the programming and operation of industrial robots, being the practical exercise performed using an ABB IRB 1400 industrial manipulator.

The following module, entitled "Autonomous mobile robotics", exposes the main characteristics of autonomous mobile robots, presenting the technologies, techniques and algorithms in this area. First of all, the kinematic relations are presented where problems like the non-holonomic restrictions will be addressed. As the autonomy is one of the main capabilities, problems like navigation, path-planning, localization and collision avoidance will be considered. The sensing problem will be treated with detail because the sensing activity is quite significant in an autonomous behavior. Also the issues of cooperation and simulation are handled in this module. The students can make experiences with real robots, using the LEGO Mindstorms NXT platforms, to better understand the main aspects of mobile robots.

Module 4 focuses on image processing and artificial intelligence in robotics. In this module, after giving the basics of image processing techniques, such as the well-known methods of edge detection, different forms of image representation and coding issues, the concept of histogram of gradients (HOG) algorithm is concisely introduced. Then a simple rule-based recognizer is gradually developed to detect a shape in an image using the HOG algorithm which is a rotation and scale invariant method [12]. The idea is to encourage the student by integrating the developed simple recognizer with a LEGO Mindstorms NXT robot, which activates itself to perform a specified task, when a learned shape is introduced via a webcam. Similar approaches to promote the engineering education using the LEGO Mindstorms NXT robot are reported in literature [13-16]. In a similar fashion, students are requested to work in a group basis to implement the describe tasks. After the classroom session, students are required to complete a work project to extend the ability of the robot to recognize new shapes which are introduced by each group. Based on this experience, the students conceived the idea that the more complex recognizer based on the artificial intelligence, such as artificial neural network, can be easily constructed and integrated to implement robotic vision applications.

Module 5, entitled "Medical robotics", is dedicated to the application of robotics to medicine, namely in rehabilitation therapies and surgery. The first lecture of the module is devoted to review the most relevant aspects of the application of robotic systems in healthcare. In the area of robotics surgery, the module details the concepts of CIS (Computer Integrated Surgery), and the robotics surgical based techniques, namely SILS (Single Incision laparoscopic surgery) and NOTES (Natural orifice transluminal endoscopic surgery). In the area of rehabilitation robotics, the following topics are addressed: use of robots for neuro-rehabilitation therapies for people with disabilities in the upper limbs, methods for the design and generation of human-like movements, human-robot haptic interface, and the admittance controller and "assistance as needed" control strategies to adapt the rehabilitation therapy to the patient state. The learning of these concepts and techniques are complemented with illustrative videos and demonstrations.

Module 6 focuses on the concept of robot as a System of Systems (SoS), i.e., a robot as service provider in an industrial SoS infrastructure. In particular, the module discusses: i) the system "robot" as a service provider in a flexible production system, ii) the system "robot" as SoS, i.e., comprising mechatronics, communication, information/services, control 
and automation systems, and iii) the application of robotic systems in different industrial and research domains.

The last module addresses entrepreneurship topics as a complementary tool to generate industrial knowledge associated to robotics. Important aspects are discussed, notably the industrial patent registration process and the Intellectual Property Right management (IPR) management.

As previously described, each module is coordinated by one partner, providing knowledge and expertise in a particular robotics topic. This allows bringing complementary knowledge and expertise in the robotics field. In some modules, different participants collaborate in the lecturing activities aiming to combine their synergies and knowledge, e.g., IPB and Lboro in module 2, and IPB and HSEL in module 7.

\section{Evaluation Methodology}

The coordinator of each module is responsible to monitor its progress, to detect deviations from the initial plan, and to inform the coordinator of the intensive course about the module progress. The module leader is responsible to setup the module, with the support of other partners according to the case, coordinating the lecture sessions and ensuring the expected outputs from the module.

At the end of the intensive course, the expected learning outcomes of the student are the following:

- Understand the context and importance of robotics in the different society sectors.

- Obtain knowledge and understand the basic concepts of industrial robotics, namely classification, kinematics, sensors and actuators, and typical applications.

- Basic knowledge about how to operate and program industrial (manipulator) robots.

- Understand and apply sensorial perception and interpretation methods for the control of robots.

- Understand and apply methods for the navigation of robots in known or unknown environments.

- Design and implement control applications for autonomous mobile robots.

- Hands-on practice on developing vision based robotic applications to recognize a shape from a given image.

- Understand the basic concepts and techniques of medical robotics applied to surgery and rehabilitation, and particularly the control techniques used for rehabilitation robots.

- Understand and apply the SoS paradigm for a robotic system.

- Understand and apply the basic concepts for industrial patent registration and IPR management.

The student achievements and learning outcomes are evaluated using mix evaluation techniques, considering three components:
- The activities developed during the intensive course and included in each module, including web quizzes (available in the e-learning platform), group assignments and laboratorial works. This component has a weight of $30 \%$.

- A final evaluation written test to be done in the last day of the course, comprising questions related to the topics addressed in the lecture modules. This component has a weight of $40 \%$.

- A mini-project report about specific robotic system topics elaborated after the presential lecture modules, weight with $30 \%$. This mini-project is elaborated individually and should be delivered in a couple of weeks after the end of the intensive course.

The students are evaluated and ranked on a scale 0-20, being each one awarded with a certificate diploma indicating the lectured contents, the number of assigned ECTS and the final reached score.

\section{IMPLEMENTATION OF THE LEARNING COURSE}

This learning program was implemented in two editions, the first one on the period from 8 to 19 of July 2013 and the second one from 7 to 18 of July 2014, both hosted at Bragança, Portugal. Table I summarizes the number of attendees (teachers and students) for these two editions.

TABLE I. ATtendANCE TO THE LEARNING COURSE

\begin{tabular}{|c|l|c|c|}
\hline Year & Country & $\boldsymbol{N}^{\boldsymbol{o}}$ Teachers & $\boldsymbol{N}^{\boldsymbol{o}}$ Students \\
\hline \multirow{4}{*}{2013} & Spain & 4 & 8 \\
\cline { 2 - 4 } & UK & 1 & 0 \\
\cline { 2 - 4 } & Germany & 1 & 1 \\
\cline { 2 - 4 } & Turkey & 1 & 4 \\
\cline { 2 - 4 } & Portugal & 3 & 5 \\
\hline \multirow{4}{*}{2014} & Spain & 4 & 9 \\
\cline { 2 - 4 } & UK & 1 & 0 \\
\cline { 2 - 4 } & Germany & 1 & 5 \\
\cline { 2 - 4 } & Turkey & 1 & 5 \\
\cline { 2 - 4 } & Portugal & 2 & 4 \\
\hline
\end{tabular}

IPB, as the coordinator institution, was responsible to manage the program organization, to setup the e-learning platform, to organize the study visit, to manage the financial resources, and to manage the accommodation and transport of the participants (teachers and students). The partner institutions were responsible for preparing the respective modules and selecting the students from their own institution. The selection of the students took into consideration several criteria, namely their academic records, the scientific area of their engineering courses and their motivation. The absence of British students is mainly justified by the fact that the teacher responsible at Lboro moved to a new university.

The information about the course was available on the Internet websites of the participating institutions, where the information was regularly updated and linked to a website created specifically to the intensive course. This website contains exhaustive information about the course, an interactive forum for students, the on-line registration mechanism, and the link for the e-learning platform. The e- 
learning platform was setup to support the implementation of the teaching activities of the course, compiling the set of pedagogical material elaborated for the several modules and including the web tests used for the evaluation assessment. Additionally, the e-learning platform hosts the work reports submitted by the students during the entire course.

The exposition of the lecture contents was complemented by visits to plants comprising robotic systems. In the first edition, the visit was to an industrial installation for processing chestnuts (i.e., Sortegel in Bragança), and the second one was to an industrial plant for processing wood (i.e., IKEA factory in Paços de Ferreira). The visits were greatly appreciated by the students that had the opportunity to consolidate the learned concepts by realizing robotic systems operating in industrial environments.

The analysis of the implementation of these two editions, and particularly the evaluation, innovation and impact will be detailed in the next sections.

\section{A. Analysis of the Feedback from Students and Lecturers}

The execution of the intensive course was evaluated taking into consideration the feedback from the different players in the project. For this purpose, the students involved in the course were invited to answer an individual questionnaire about, amongst others, the course structure and organization, pedagogical and didactic activities. The questionnaire uses the Likert scale for the majority of answers, i.e., (1) Not at all satisfied, (2) Not very satisfied, (3) Fairly satisfied, (4) Very satisfied, and (5) Very much satisfied.

The feedback from the students showed that they were highly motivated and gained confidence in the robotics field. Namely, $79 \%$ of the students were very or very much satisfied with the duration of the course, which reinforces the benefits of having an intensive course concentrated in two weeks. However, only $57 \%$ were very or very much satisfied with the dates, which can be justified with the overlapping of the course with the traditional beginning of the holiday period in academia. The factors that mostly motivated the participation of the students in the course were mainly the academic $(86 \%)$, cultural (79\%), practice of foreign language (93\%) and European experience (79\%).

Fig. 3 summarizes the feedback achieved from the students regarding the satisfaction with the academic activities and the pedagogical aspects of the course.

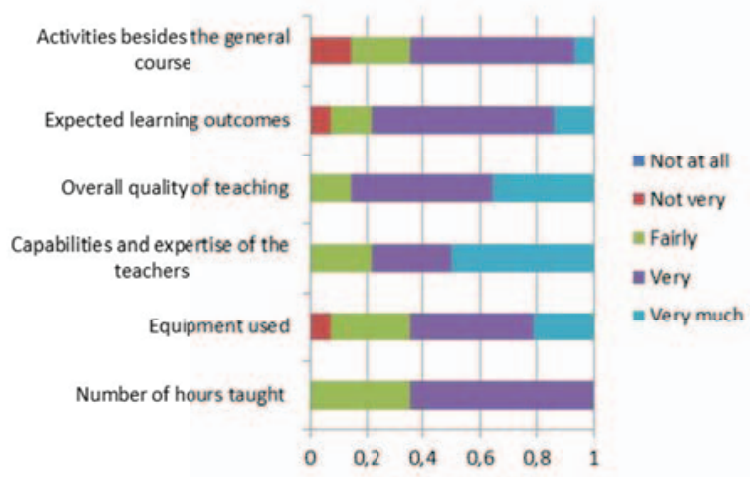

Fig. 3. Level of satisfaction with the academic and pedagogical aspects.
The analysis of the results allows to verify that all items were favorable scored by the students. Particularly, students recognized the overall quality of teaching $(86 \%)$ and the capabilities and expertise of the teachers (79\%). A minority (only $7 \%$ ) was disappointed with the equipment used, probably due the reduced number of industrial manipulator robots available for the course (note that this equipment is very expensive). Some students (14\%) were expecting more (social) activities besides the general lecturing course.

Another important indicator to measure the success of the learning course was the very positive general view of the participants at the end of the intensive course, either by teachers or students, indicating their participation in the learning program as a successful experience. The analysis of Fig. 4, which illustrates the students' feedback related to the overall evaluation of the course, allows to conclude that $43 \%$ of the students evaluated the course as excellent and 50\% as good.

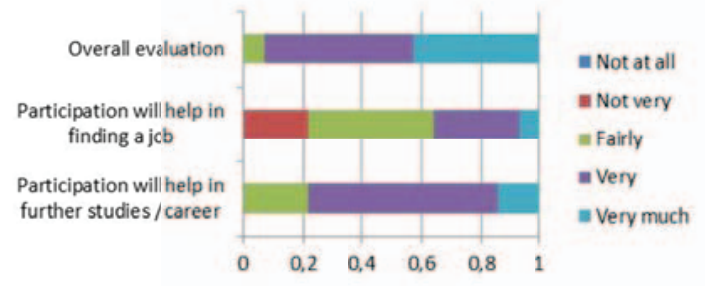

Fig. 4. Overall evaluation of the course.

An additional important conclusion is that the students recognize the importance of the participation in the learning course for their further studies / career (79\%), but only $36 \%$ are convinced that this will help them to find a job.

A complementary feedback was provided by the modules' coordinators, which elaborated a report about the execution of the module, including suggestions of improvements to be introduced in future editions of the intensive course. The feedback from the questionnaires and the reports allowed to extract conclusions and to detect malfunctions, aiming to make improvements in future editions. As example, the feedback from the first course edition was used to slightly improve the second edition, being reflected in the increase of the attendance of students from Germany.

\section{B. Innovation and Impact}

The innovation of this learning program is related to the establishment of a transnational course in the robotics field, with the contribution of different institutions with recognized knowledge and experiences in different and complementary knowledge areas. Additionally, the multidisciplinary aspect of robotics, congregating knowledge from different scientific domains, allows an innovative environment for the opportunity to implement the knowledge exchange and different learning practices, however aligned with the Bologna process.

These aspects constitute a valuable and challenging project to improve the multilateral cooperation between higher education institutions. In a similar way, and aligned with the Bologna principles of mobility of students during their studies, the intensive course contributes to enlarge individual students and teaching mobility between institutions (note that besides 
the local students and teachers, the learning course was attended by an average of 16 students and 7 teachers in mobility).

The network established during the intensive course, based on complementary knowledge in robotic systems field, allowed to improve the knowledge and competences of each partner, and also the application of innovative practices in education and learning processes. In fact, the different perspectives about the robotic systems field, but also the learning practices, brought to the project by the different participating institutions, could be analyzed, tested, compared and merged into innovative learning contents and practices. In fact, this environment permitted to exchange and share experiences, knowledge and learning practices in the field of robotics, fundamental for the development of future common projects together.

The use of an e-learning platform combined with innovative learning methodologies, contents and practices for the robotic systems field allowed to support the establishment of an innovative ICT-based platform supporting the lifelong learning. Namely, the contents for the learning course were developed using multimedia platforms, e.g., based on powerpoint slides and illustrative videos, and considering simulation tools for robotic systems. The developed e-learning contents may be used by each participant in its local learning curricula.

The inclusion of a module in the intensive course handling with students' entrepreneurial competences, namely addressing topics like industrial patent registration process and IPR management, contributes to overcome an important gap in this area. In fact, the topics addressed by this module are nowadays crucial in the engineering curricula to stimulate the entrepreneurial competences of the students.

Another important benefit was the establishment and strength of international academic/scientific networks, for example in terms of Erasmus partnerships by improving the mutual recognition of partner institutions and reinforcing the Erasmus mobility programs between institutions. Additionally, a solid network of contacts was established with the aim of studying the possibility of implementing joint or double degree programs and developing future partnerships under the Erasmus + and Horizon 2020 programs.

\section{CONCLUSIONS}

This paper describes the multidisciplinary and transnational experience gathered from the implementation of the intensive course on robotic systems, and particularly the implemented learning practices and also the new forms of research cooperation in the robotics topics.

The implementation of the intensive course highlighted its importance in the development of human resources with expertise in the areas of robotic systems. Particularly, the establishment of an international network that brought together experts in different scientific knowledge fields contributed to share learning practices and to complement the knowledge of the different technology topics. This type of initiative provides a unique learning environment and allows to offer knowledge and skills to graduate students who will join the labor market in the very near future that no institution could provide alone.

The results achieved in this learning course, and particularly the shared learning practices, can be used by each participant to improve its local learning curricula and easily disseminated for other high-education institutions as good learning practices in the robotics field.

\section{ACKNOWLEDGMENT}

The work described in this paper was financially supported by the Lifelong Learning Programme Erasmus, under the projects n. 2012-1-PT1-ERA10-12529 and 2013-1-PT1ERA10-16656.

\section{REFERENCES}

[1] B. Siciliano, O. Khatib (eds.), "Handbook on Robotics", Springer, 2008.

[2] M. T. Restivo, J. Mendes, A. M. Lopes, C. M. Silva, F. Chouzal, "A Remote Lab in Engineering Measurement", IEEE Trans. on Industrial Electronics, vol. 56, nº12, pp. 4436-4843, 2009.

[3] J. G. Zubía, I. Angulo, J. Irurzun, P. Orduña, J. Ruiz, U. Hernández, M. Castro, E.S. Cristóbal, "Easily Integrable Platform for the Deployment of a Remote Laboratory for Microcontrollers", International Journal of Online Engineering, vol. 6, no. 3, pp. 26-31, 2011.

[4] Summer School on Social Human-Robot Interaction, available at https://hrisummerschool15.wordpress.com/ (accessed on $5^{\text {th }}$ May 2015).

[5] Robotic Vision Summer School, available at http://roboticvision.org/events/rvss-summer-school/ (accessed on $5^{\text {th }}$ May 2015).

[6] Summer School on Surgical Robotics, available at http://www.lirmm.fr/numev/index.php/events/96-7th-summer-schoolon-surgical-robotics-2-9-september (accessed on $5^{\text {th }}$ May 2015).

[7] Summer School on Agricultural Robotics, available at http://eventegg.com/ssar-2015/ (accessed on $5^{\text {th }}$ May 2015).

[8] European Comission, "Lifelong Learning Programme", available at http://ec.europa.eu/education/tools/llp_en.htm (accessed on 26/04/2015).

[9] A. Rojko, K. Kozlowski, "Lifelong Education in Robotics and Mechatronics", 17th International Conference on Methods and Models in Automation and Robotics (MMAR), pp. 343 - 348, 2012.

[10] European Comission, "European Credit Transfer and Accumulation System", avalable at http://ec.europa.eu/education/tools/ects_en.htm (accessed on 26/04/2015).

[11] G. Zurita, B. Hasbun, N. Baloian, O. Jerez, "A Blended Learning Environment for Enhancing Meaningful Learning Using 21st Century Skills", Emerging Issues in Smart Learning, Lecture Notes in Educational Technology, Springer, pp 1-8, 2015.

[12] B. Demirci, O. Arslan, N.S. Tunaboylu, H. Altun, "Implementing HOG \& AMDF Based Shape Detection Algorithm for Computer Vision \& Robotics Education Using LEGO Mindstorms NXT", Proc. of the International Conference on Technological Advances in Electrical, Electronics and Computer Engineering (TAEECE), pp. 288-293, 2013.

[13] F. Mondada et al., "The e-puck, a Robot Designed for Education in Engineering", Proceedings of the $9^{\text {th }}$ Conference on Autonomous Robot Systems and Competitions, pp. 59-65, 2009.

[14] J.M. Gómez-de-Gabriel, A. Mandow, J. Fernández-Lozano, A.J. GarcíaCerezo, "Using LEGO NXT mobile robots with LabVIEW for Undergraduate Courses on Mechatronics", IEEE Transactions on Education, vol. 54, n. 1, pp. 41-47, 2011.

[15] A. Behrens, L. Atorf, D. Schneider, T. Aach, "Key Factors for Freshmen Education using MATLAB and LEGO Mindstorms", Intelligent Robotics and Applications, LNCS 7101, Springer, pp 553-562, 2011.

[16] P. Ranganathan, R. Schultz, M. Mardani, "Use of LEGO NXT Mindstorms Robot in Engineering Education", Proceedings of the 2008 ASEE North Midwest Sectional Conference, 2008. 